\title{
Sleep Fragmentation and Risk of Automobile Accidents in Patients with Obstructive Sleep Apnea
}

\section{-Sleep Fragmentation and Automobile Accidents in OSA}

\author{
Akiko Noda ${ }^{*}$, Fumihiko Yasuma ${ }^{2}$, Seiko Miyata ${ }^{3}$, Kunihiro Iwamoto ${ }^{3}$, \\ Yoshinari Yasuda ${ }^{4}$, Norio Ozaki ${ }^{3}$ \\ ${ }^{1}$ Chubu University Graduate School of Life and Health Sciences, Kasugai, Japan \\ ${ }^{2}$ Department of Internal Medicine, National Hospital Organization Suzuka National Hospital, Suzuka, Japan \\ ${ }^{3}$ Department of Psychiatry, Nagoya University Graduate School of Medicine, Nagoya, Japan \\ ${ }^{4}$ Department of CKD Initiatives, Nagoya University Graduate School of Medicine, Nagoya, Japan \\ Email: *anoda@isc.chubu.ac.jp
}

How to cite this paper: Noda, A., Yasuma, F., Miyata, S., Iwamoto, K., Yasuda, Y. and Ozaki, N. (2019) Sleep Fragmentation and Risk of Automobile Accidents in Patients with Obstructive Sleep Apnea. Health, 11, 171-181.

https://doi.org/10.4236/health.2019.112015

Received: December 24, 2018

Accepted: February 16, 2019

Published: February 19, 2019

Copyright $\odot 2019$ by author(s) and Scientific Research Publishing Inc. This work is licensed under the Creative Commons Attribution International License (CC BY 4.0).

http://creativecommons.org/licenses/by/4.0/

\begin{abstract}
Objectives: Automobile accidents related to obstructive sleep apnea (OSA) represent an important public health concern. Frequent arousal response during sleep is responsible for the symptoms of daytime sleepiness and an increased risk of automobile accidents in patients with OSA. We therefore investigated the potential relationships between the intensity of arousal and occurrence of automobile accidents in OSA. Methods: We determined the incidence of automobile accidents in the past 5 years among 51 men with OSA (age, $58.5 \pm 10.4$ years) using a questionnaire. Daytime sleepiness was rated with the Epworth Sleepiness Scale (ESS). We calculated an automobile accident score, with two points per automobile accident causing damage and one point per near miss. Standard polysomnography was performed for all patients, and arousals were classified as electroencephalographic (EEG) arousal of an abrupt shift in EEG frequency alone and Movement arousal, which was defined as EEG arousal with increased electromyographic activity persisting for $\geq 3 \mathrm{~s}$. The number of EEG or Movement arousals per hour (arousal index) was determined. Results: The Movement arousal index was significantly greater in the 27 patients who experienced at least one automobile accident causing damage than in the resting 24 patients who had no history of automobile accidents. Multiple regression analysis including age, body mass index, and sleep parameters revealed that the Movement arousal index was the most significant factor of risk for automobile accidents $(\beta=0.563, P$ $=0.017)$ as well as the ESS score $(\beta=0.417, P=0.022)$. Conclusion: Move-
\end{abstract}


ment arousal during sleep contributes to daytime sleepiness and the resulting frequent involvement of OSA patients in automobile accidents.

\section{Keywords}

Sleep Apnea, Arousal, Automobile Accidents, Daytime Sleepiness

\section{Introduction}

In the United States, sleepiness is presumed to be a principal cause of $15 \%-20 \%$ of traffic accidents [1]. A recent meta-analysis showed that sleepiness at the wheel results in a 2.5 -fold increase in motor vehicle accidents compared with other reasons [2]. Although the prevention of drowsy driving is not only relevant to individual safety, but also a serious public health concern, there is still a lack of scientific knowledge and public education necessary to prevent drowsy driving [3] [4]. Sleepiness is caused by various factors such as sleep disorder, sleep deprivation, alcohol consumption, and drug use. Considering the negative impacts of automobile accidents on society and the quality of human life, an assessment of the risk of such accidents is an important responsibility in the practice of sleep medicine.

Obstructive sleep apnea (OSA) is one of the major medical causes of excessive daytime sleepiness [5] [6] [7]. The incidence of automobile accidents in individuals with OSA is 2 - 4 times more prevalent than those without this condition [8] [9] [10]. In general, individuals with OSA show poor driving performance, as indicated by lapses of attention and increase in drifting in lane position in driving simulators [11]. Sleep fragmentation is caused by repeated episodes of arousal on termination of apnea or hypopnea, and consequent poor sleep quality during nighttime adversely affects daytime alertness [6] [7] [8]. Thus, frequent arousals during sleep likely contribute to the increased risk of automobile accidents in OSA. However, to our knowledge, the impact of transient arousal from sleep on both the daytime sleepiness and automobile accidents in patients with OSA has not been systematically analyzed.

We hypothesized that episodes of arousal from sleep are responsible for the symptoms of daytime sleepiness and an increased risk of automobile accidents in OSA. We therefore investigated the potential relationships of movement arousal, electroencephalographic (EEG) arousal, and nocturnal oxygen desaturation with occurrence of automobile accidents and severity of daytime sleepiness in patients with OSA.

\section{Methods}

\subsection{Subjects}

Subjects were recruited from patients underwent polysomnography (PSG) at the Nagoya University Hospital, and we evaluated 51 consecutive Japanese male pa- 
tients with OSA (aged 45 to 78 years; mean \pm SD, $58.5 \pm 10.4$ years). Individuals with any psychiatric disorder, epilepsy, narcolepsy, or periodic leg movement as well as shift workers were excluded from the study. As control subjects, we also investigated 56 age-matched (55.8 \pm 10.6 years) healthy men. Patients were informed in detail of the purpose of the study, from whom we obtained informed consent. The study protocol was approved by the appropriate institutional review committee.

\subsection{Polysomnography (PSG)}

Standard PSG [12] was performed for all patients with OSA at Nagoya University Hospital. Electroencephalogram, electrooculogram, electromyogram (EMG), and electrocardiogram were continuously recorded. Respiration was monitored with an oronasal thermistor and thoracoabdominal strain gauges. Apnea was defined as a cessation of airflow through the mouth and nose for $\geq 10$ s, and hypopnea was defined as a reduction in airflow associated with either an oxygen desaturation of $>3 \%$ or arousal, also for $\geq 10$ s. The apnea-hypopnea index (AHI) was determined as the number of apnea and hypopnea episodes per hour. Individuals with an AHI of $\geq 5 / h$ and symptomatic daytime sleepiness were diagnosed as OSA [13]. The time during which the nocturnal oxygen saturation $\left(\mathrm{SpO}_{2}\right)$ was $<90 \%$ (oxygen desaturation time, or ODT) and the minimum $\mathrm{SpO}_{2}$ achieved during sleep were measured with a pulse oximeter (Pulsox 7; Minolta, Tokyo, Japan).

We assessed the structure of sleep in terms of sleep efficiency and the percentage contributions of each sleep stage [stage 1, stage 2, stages 3 and 4, or rapid eye movement (REM)] to overall sleep [12]. EEG arousal after termination of apnea-hypopnea was identified according to the 1992 recommendation of the American Sleep Disorders Association [14]. We determined the number of EEG arousals per hour (EEG arousal index).

Furthermore, polysomnographic arousal was classified into two specific grades by visual analysis of recordings: grade 1 (EEG arousal), representing an abrupt shift in EEG frequency; and grade 2 (Movement arousal) [15] [16] [17], in which EEG arousal was associated with an increase in EMG amplitude, persisting for $\geq 3 \mathrm{~s}$. We measured the number of movement arousals per hour (Movement arousal index).

\subsection{Epworth Sleepiness Scale (ESS) and Accident Score}

Daytime sleepiness was rated subjectively by the 51 patients with OSA and 56 control subjects using the ESS [18]. In the ESS questionnaire, subjects were asked to rate the likelihood of dozing off or falling asleep in each of eight different situations according to the following scale: 0 , no chance; 1 , slight chance; 2 , moderate chance; and 3, high chance. Total ESS scores thus could range from 0 to 24. We also retrospectively calculated an automobile accident score for each subject over the previous 5 years, with two points per automobile accident causing damage and one point per near miss, using a self-report questionnaire. 


\subsection{Statistical Analysis}

Results were expressed as means $\pm \mathrm{SD}$ and were analyzed using non-paired t-test. Categorical variables were compared using the $\mathrm{x}^{2}$ test. A $P$ value of $<0.05$ was considered statistically significant. Correlations were determined by linear regression analyses. Multiple regression analysis based on a stepwise forward selection method including age, body mass index (BMI) and sleep parameters was performed to determine significant risk factors for automobile accidents and daytime sleepiness in individuals with OSA. Statistical analyses were performed using the IBM SPSS Statistics version 23 (IBM, Chicago, IL).

\section{Results}

Automobile accidents resulting in damage or near misses in the past 5 years were reported by $52.9 \%$ and $45.1 \%$ of OSA patients, respectively. Both types of occurrence were more prevalent in OSA patients than in the age and sex-matched controls (9.1 and 25.0\%, respectively). The time spent for driving per week did not differ significantly between the two groups. Both the accident and ESS scores were significantly greater in the patients with OSA than in control subjects (Table 1).

Movement arousal index was significantly greater in the 27 OSA patients who experienced at least one automobile accident resulting in damage than in the 24 patients without automobile accidents (Table 2). Accident score as well as Movement arousal index was also significantly greater in the patients with ESS score of $\geq 10$ than in those with ESS score of $<10$ (Table 3 ).

The accident score was significantly correlated with the AHI $(\mathrm{r}=0.448, P=$ $0.033)$, ODT ( $\mathrm{r}=0.413, P=0.008)$, ESS score $(\mathrm{r}=0.514, P<0.0006)$, Movement arousal index $(\mathrm{r}=0.563, P<0.0001)$, and EEG arousal index $(\mathrm{r}=0.519, P<$ $0.0004)$. ESS score was significantly correlated with the ODT $(\mathrm{r}=0.370, P=$ $0.018)$, Movement arousal index $(\mathrm{r}=0.417, P=0.006)$, and EEG arousal index ( $\mathrm{r}$

Table 1. Characteristics of the study subjects, including 5-year history of automobile accidents.

\begin{tabular}{cccc}
\hline Characteristics & $\begin{array}{c}\text { OSA patients } \\
(n=51)\end{array}$ & $\begin{array}{c}\text { Controls } \\
(n=56)\end{array}$ & $P$ value \\
\hline Age (years) & $58.5 \pm 10.4$ & $55.8 \pm 10.6$ & 0.281 \\
Height $(\mathrm{cm})$ & $165.2 \pm 5.0$ & $167.1 \pm 6.3$ & 0.069 \\
Weight $(\mathrm{kg})$ & $72.1 \pm 13.7$ & $65.8 \pm 10.6$ & 0.052 \\
BMI $\left(\mathrm{kg} / \mathrm{m}^{2}\right)$ & $26.4 \pm 4.4$ & $23.5 \pm 2.8$ & $<0.001$ \\
Accident score & $2.9 \pm 3.1$ & $0.89 \pm 1.6$ & $<0.001$ \\
ESS score & $10.8 \pm 6.7$ & $5.0 \pm 2.9$ & $<0.001$ \\
Subjects with: & & & $<0.001$ \\
Automobile accidents $(\%)$ & $27(52.9)$ & $5(9.1)$ & $<0.001$ \\
\hline Near misses (\%) & $23(45.1)$ & $14(25.0)$ & \\
\hline
\end{tabular}

OSA, obstructive sleep apnea; BMI, body mass index; ESS, Epworth Sleepiness Scale. 
Table 2. Sleep parameters and ESS score for 51 OSA patients classified according to history of automobile accidents.

\begin{tabular}{cccc}
\hline Characteristics & $\begin{array}{c}\text { No accident } \\
(n=24)\end{array}$ & $\begin{array}{c}\text { One or more accidents } \\
(n=27)\end{array}$ & $P$ value \\
\hline Age (years) & $60.0 \pm 10.5$ & $57.2 \pm 10.4$ & 0.183 \\
Height $(\mathrm{cm})$ & $166.0 \pm 4.9$ & $164.3 \pm 5.1$ & 0.231 \\
Weight $(\mathrm{kg})$ & $70.4 \pm 12.0$ & $73.5 \pm 15.2$ & 0.457 \\
BMI (kg/m $\left.{ }^{2}\right)$ & $25.5 \pm 4.0$ & $27.1 \pm 4.6$ & 0.220 \\
AHI $(/ \mathrm{h})$ & $32.5 \pm 17.3$ & $42.4 \pm 18.6$ & 0.033 \\
Minimum SpO $(\%)$ & $62.0 \pm 21.5$ & $67.8 \pm 14.8$ & 0.485 \\
ODT (min) & $66.9 \pm 66.3$ & $85.5 \pm 77.5$ & 0.154 \\
Sleep efficiency $(\%)$ & $84.1 \pm 12.4$ & $77.1 \pm 11.4$ & 0.065 \\
\%Stage 1 & $20.5 \pm 10.6$ & $25.3 \pm 8.3$ & 0.113 \\
\%Stage 2 & $44.7 \pm 9.7$ & $38.0 \pm 11.8$ & 0.050 \\
\%Stages 3 and 4 & $1.9 \pm 5.7$ & $0.7 \pm 1.4$ & 0.359 \\
\%REM & $15.4 \pm 8.9$ & $12.4 \pm 6.7$ & 0.219 \\
EEG arousal index $(/ \mathrm{h})$ & $28.2 \pm 16.9$ & $41.5 \pm 17.0$ & 0.016 \\
Movem score & $25.3 \pm 16.7$ & $36.4 \pm 17.2$ & 0.041 \\
Accident score & $1.14 \pm 0.56$ & $4.88 \pm 3.34$ & $<0.001$ \\
\hline arousal index $(/ \mathrm{h})$ & $10.9 \pm 6.72$ & $11.9 \pm 6.94$ & 0.621 \\
\hline
\end{tabular}

$\mathrm{BMI}$, body mass index; $\mathrm{AHI}$, apnea-hypopnea index; $\mathrm{SpO}_{2}$, oxygen saturation; ODT, oxygen desaturation time; REM, rapid eye movement; EEG, electroencephalogram; ESS, Epworth Sleepiness Scale.

$=0.337, P=0.031$ ) (Table 4). Multiple regression analysis revealed that the Movement arousal index was the most significant factor of risk for automobile accidents $(\beta=0.563, P=0.017)$ as well as ESS score $(\beta=0.417, P=0.022)$ (Table 4).

After the successful treatment with continuous positive airway pressure in 24 patients with OSA, ESS score was significantly decreased from $14.5 \pm 5.5$ to $7.3 \pm$ 5.0 and automobile accidents no longer occurred thereafter.

\section{Discussion}

Automobile accidents caused by individuals with OSA represent an important public health problem. We have shown that arousal was the most significant factor in both the risk for automobile accidents and daytime sleepiness. Our results suggest that the frequent Movement arousal and the consequent sleep fragmentation contribute to the increased risk of automobile accidents in individuals with OSA, presumably as a result of excessive daytime sleepiness and lack of concentration during motor vehicle driving.

Our definitions of EEG arousal as an abrupt shift in EEG frequency alone and Movement arousal as EEG arousal plus an increase in the amplitude of submental EMG activity during NREM sleep, which allowed us to make important 
Table 3. Sleep parameters and accident score for 51 OSA patients classified according to ESS score.

\begin{tabular}{|c|c|c|c|}
\hline Characteristics & $\begin{array}{c}\text { ESS }<10 \\
(n=24)\end{array}$ & $\begin{array}{c}\mathrm{ESS} \geq 10 \\
(n=27)\end{array}$ & $P$ value \\
\hline Age (years) & $61.5 \pm 9.4$ & $55.9 \pm 10.7$ & 0.982 \\
\hline Height $(\mathrm{cm})$ & $165.7 \pm 5.2$ & $164.7 \pm 4.9$ & 0.700 \\
\hline Weight (kg) & $66.7 \pm 9.1$ & $76.9 \pm 15.3$ & 0.035 \\
\hline BMI $\left(\mathrm{kg} / \mathrm{m}^{2}\right)$ & $24.3 \pm 3.1$ & $28.2 \pm 4.5$ & 0.010 \\
\hline $\mathrm{AHI}(/ \mathrm{h})$ & $30.7 \pm 16.1$ & $44.0 \pm 18.5$ & 0.027 \\
\hline Minimum $\mathrm{SpO}_{2}(\%)$ & $68.2 \pm 19.3$ & $62.6 \pm 16.9$ & 0.460 \\
\hline ODT (min) & $36.3 \pm 45.0$ & $120.3 \pm 80.0$ & 0.001 \\
\hline Sleep efficiency (\%) & $78.3 \pm 14.3$ & $79.3 \pm 12.3$ & 0.999 \\
\hline \%Stage 1 & $21.1 \pm 8.9$ & $23.4 \pm 9.5$ & 0.442 \\
\hline \%Stage 2 & $42.3 \pm 9.1$ & $39.6 \pm 13.4$ & 0.512 \\
\hline$\%$ Stages 3 and 4 & $1.0 \pm 1.5$ & $0.5 \pm 1.3$ & 0.099 \\
\hline$\%$ REM & $14.5 \pm 8.1$ & $15.6 \pm 6.7$ & 0.408 \\
\hline EEG arousal index (/h) & $26.1 \pm 15.1$ & $40.7 \pm 17.8$ & 0.010 \\
\hline Movement arousal index $(/ \mathrm{h})$ & $21.3 \pm 15.0$ & $47.1 \pm 16.7$ & 0.004 \\
\hline Accident score & $1.7 \pm 2.2$ & $3.9 \pm 3.5$ & 0.004 \\
\hline
\end{tabular}

BMI, body mass index; AHI, apnea-hypopnea index; $\mathrm{SpO}_{2}$, oxygen saturation; ODT, oxygen desaturation time; REM, rapid eye movement; EEG, electroencephalogram; ESS, Epworth Sleepiness Scale.

observations in the present investigation. The Movement arousal index was thus the most significant predictor of ESS score or accident score, with the EEG arousal index being the secondly predictor. Movement arousal, rather than EEG arousal, is therefore likely to result in sleep fragmentation and consequent daytime sleepiness in individuals with OSA. These observations emphasize the clinical importance for assessing the intensity of arousal on the routine PSG, which was also stressed in the criteria by the American Academy of Sleep Medicine task force [13]. Various simplified screening tests for OSA have a methodological limitation. For example, home sleep studies can be performed at relatively low cost, but the reliability of the results is compromised by the lack of information on arousal. Given the cost-utility relation of standard PSG versus home screening, the application of PSG to diagnose and treat OSA patients seems to be a worthwhile investment [19]. We therefore believe that evaluation of both the frequency and intensity of arousal by routine PSG represents a potential tool to identify the jeopardized patients with OSA-related automobile accidents.

Changes in blood pressure and heart rate in response to sleep apnea-hypopnea depend on the intensity of arousal, as indicated by the shift in EEG frequency or the surge in EMG activity [15] [20] [21]. The intensity of arousal is also modified by the level of breathing effort required to counteract the narrowed or obstructed upper airway [17]. Arousal and subsequent termination of apnea in 
Table 4. Simple correlation and multiple regression analysis between sleep parameters and accident score or ESS score.

\begin{tabular}{|c|c|c|c|c|}
\hline \multirow[b]{3}{*}{ Characteristics } & \multicolumn{4}{|c|}{ Accident score } \\
\hline & \multicolumn{2}{|c|}{ Simple correlation } & \multicolumn{2}{|c|}{ Multiple regression analysis } \\
\hline & $r$ & $P$ value & $\beta$ & $P$ value \\
\hline Age & -0.355 & 0.024 & -0.329 & 0.479 \\
\hline BMI & 0.266 & 0.073 & 0.278 & 0.281 \\
\hline ESS & 0.514 & 0.0006 & 0.513 & 0.043 \\
\hline AHI & 0.448 & 0.033 & 0.416 & 0.408 \\
\hline Minimum $\mathrm{SpO}_{2}$ & -0.092 & 0.574 & & \\
\hline ODT & 0.413 & 0.008 & 0.241 & 0.366 \\
\hline Sleep efficiency & 0.094 & 0.566 & & \\
\hline$\%$ Stage 1 & 0.241 & 0.134 & & \\
\hline \%Stage 2 & 0.015 & 0.926 & & \\
\hline$\%$ Stage $3+4$ & -0.200 & 0.218 & & \\
\hline$\%$ REM & 0.008 & 0.963 & & \\
\hline Movement arousal index & 0.563 & $<0.0001$ & 0.563 & 0.017 \\
\hline \multirow[t]{3}{*}{ EEG arousal index } & 0.519 & 0.0004 & & \\
\hline & \multicolumn{4}{|c|}{ ESS score } \\
\hline & \multicolumn{2}{|c|}{ Simple correlation } & \multicolumn{2}{|c|}{ Multiple regression analysi } \\
\hline Characteristics & $r$ & $P$ value & $\beta$ & $P$ value \\
\hline Age & -0.153 & 0.347 & -0.145 & 0.870 \\
\hline BMI & -0.261 & 0.104 & 0.259 & 0.213 \\
\hline AHI & 0.330 & 0.372 & 0.309 & 0.451 \\
\hline Minimum $\mathrm{SpO}_{2}$ & -0.010 & 0.951 & & \\
\hline ODT & 0.370 & 0.018 & 0.341 & 0.557 \\
\hline Sleep efficiency & 0.074 & 0.652 & & \\
\hline \%Stage 1 & 0.075 & 0.648 & & \\
\hline \%Stage 2 & 0.010 & 0.952 & & \\
\hline$\%$ Stage $3+4$ & -0.260 & 0.106 & & \\
\hline$\%$ REM & 0.157 & 0.337 & & \\
\hline Movement arousal index & 0.417 & 0.006 & 0.417 & 0.022 \\
\hline EEG arousal index & 0.337 & 0.031 & 0.337 & 0.096 \\
\hline
\end{tabular}

BMI, body mass index; AHI, apnea-hypopnea index; $\mathrm{SpO}_{2}$, oxygen saturation; ODT, oxygen desaturation time; REM, rapid eye movement; EEG, electroencephalogram; ESS, Epworth Sleepiness Scale.

OSA patients are thus shown to occur at similar levels of the inspiratory effort [17]. Moreover, sleep fragmentation concomitant with surges in blood pressure and heart rate has been shown to result in daytime sleepiness that impairs psychomotor function even in healthy individuals [21]. The autonomic activation induced by Movement arousal, a more intense form of arousal than EEG 
arousal alone, is therefore likely to contribute to symptoms of daytime sleepiness and, consequently, to an increased risk of automobile accidents in patients with OSA.

Although the causal and result relationships among nocturnal hypoxia, daytime sleepiness, and occurrence of automobile accidents in patients with OSA have not yet been determined, the severity of daytime sleepiness is more closely correlated with the measures of sleep fragmentation than severity of nocturnal hypoxemia [17] [21] [22] [23]. In the present study, we found that the arousal index was the most reliable predictor of the occurrence of automobile accidents. Moreover, we also showed that the accident and ESS scores were significantly correlated with the severity of nocturnal hypoxemia. Frequent episodes of nocturnal oxygen desaturation might influence arousal threshold and result in an overall abnormal sleep structure that leads to an impaired circadian rhythm in autonomic activity [24]. Thus, both frequent arousals and nocturnal oxygen desaturation may increase the risks of automobile accidents in patients with OSA. No study as ever reported that the effects of arousal intensity on automobile accidents or daytime sleepiness. Punjabi et al. examined the relations between the PSG parameters and subjective severity of daytime sleepiness in 741 patients with sleep-disordered breathing and concluded that the AHI, nocturnal hypoxemia, and sleep fragmentation were independent determinants of daytime sleepiness in individuals with this condition [25] consistent with our present results.

Regarding our methodological limitations, this study was retrospective and the control subjects might not be representative of the general population. This was partly because detailed data on automobile accidents could not be obtained from the Government, Police, insurance companies, or other sources in Japan. Furthermore, we determined the history of automobile accidents with a self-report questionnaire, which might be biased. However, a previous study from the Japanese group revealed similarly frequent automobile accidents in patients with OSA (accidents, 33\%; near misses, 82\%) [26]. Further study seems mandatory to elucidate the relationships between the sleep parameters and accident score in healthy subjects.

\section{Conclusion}

We have demonstrated a close relation among the intensity of arousal, occurrence of automobile accidents and severity of daytime sleepiness in patients with OSA. We propose that frequent arousals, especially the Movement arousals in the standard PSG could be a stratification marker for OSA patients with critical risk of automobile accidents, for which the prompt and proper treatment to relieve symptoms of excessive daytime sleepiness are required.

\section{Conflicts of Interest}

The authors declare no conflicts of interest associated with this manuscript. 


\section{References}

[1] Schreier, S., Banks, C. and Mathis, J. (2018) Driving Simulators in the Clinical Assessment of Fitness to Drive in Sleepy Individuals: A Systematic Review. Sleep Medicine Reviews, 38, 86-100. https://doi.org/10.1016/j.smrv.2017.04.004

[2] Bioulac, S., Franchi, J.M., Arnaus, M., Sagaspe, P., Moore, N., Salvo, F. and Philip, P. (2017) Risk of Motor Vehicle Accidents Related to Sleepiness at the Wheel: A Systematic Review and Meta-Analysis. Sleep, 40.

https://doi.org/10.1093/sleep/zsx134

[3] Watson, N.F., Morgenthaler, T., Chervin, R., Carden, K., Kirsch, D., Kristo, D., Malhotra, R., Martin, J., Ramar, K., Rosen, I., Weaver, T. and Wise, M. (2015) Confronting Drowsy Driving: The American Academy of Sleep Medicine Perspective. Journal of Clinical Sleep Medicine, 11, 1335-1336. https://doi.org/10.5664/jcsm.5200

[4] Noda, A., Miyaji, M., Wakuda, Y., Hara, H., Yasuma, F., Fukuda, T., Iwamoto, K. and Ozaki, N. (2015) Simultaneous Measurement of Heart Rate Variability and Blinking Duration to Predict Sleep Onset and Drowsiness in Drivers. Journal of Sleep Disorders \& Therapy, 4, 213. https://doi.org/10.4172/2167-0277.1000213

[5] Karimi, M., Hender, J., Habel, H., Neman, O. and Grote, L. (2015) Sleep Apnea-Related Risk of Motor Vehicle Accidents Is Reduced by Continuous Positive Airway Pressure: Swedish Traffic Registry Data. Sleep, 38, 341-349. https://doi.org/10.5665/sleep.4486

[6] Li, Y., Vgontzas, A., Kritikou, L., Fernandez-Mendoza, J., Basta, M., Slobodanka, P., Gaines, J. and Bixler, E. (2017) Psychomotor Vigilance Test and Its Association with Daytime Sleepiness and Inflammation in Sleep Apnea: Clinical Implications. Jour nal of Clinical Sleep Medicine, 13, 1049-1056. https://doi.org/10.5664/jcsm.6720

[7] Huamaní, C., Rey de Castro, J. and Mezones-Holguín, E. (2014) Sleepiness and Nocturnal Hypoxemia in Peruvian Men with Obstructive Sleep Apnea. Sleep and Breathing, 18, 467-473. https://doi.org/10.1007/s11325-013-0907-3

[8] Strohl, K.P., Brown, D.B., Collop, N., George, C., Grunstein, R., Han, F., Kline, L., Malhotra, A., Pack, A., Phillips, B., Rodenstein, D., Schwab, R., Weaver, T. and Wilson, K. (2013) An Official American Thoracic Society Clinical Practice Guideline: Sleep Apnea, Sleepiness, and Driver Risk in Noncommercial Drivers. An Update of a 1994 Statement. American Journal of Respiratory and Critical Care Medicine, 187, 1259-1266. https://doi.org/10.1164/rccm.201304-0726ST

[9] Ward, K.L., Hillman, D.R., James, A., Bremner, A.P., Simpson, L., Cooper, M.N., Palmer, L.J., Fedson, A.C., Mukherjee, S. and Hillman, D.R. (2013) Excessive Daytime Sleepiness Increases the Risk of Motor Vehicle Crash in Obstructive Sleep Apnea. Journal of Clinical Sleep Medicine, 9, 1013-1021. https://doi.org/10.5664/jcsm.3072

[10] Mulgrew, A.T., Nasvadi, G., Butt, A., Cheema, R., Fox, N., Fleetham, J.A., Ryan, C.F., Cooper, P. and Ayas, N.T. (2008) Risk and Severity of Motor Vehicle Crashes in Patients with Obstructive Sleep Apnoea/Hypopnoea. Thorax, 63, 536-541. https://doi.org/10.1136/thx.2007.085464

[11] Gieteling, E.W., Bakker, M.S., Hoekema, A., Maurits, N.M., Brouwer, W.H. and van der Hoeven, J.H. (2012) Impaired Driving Simulation in Patients with Periodic Limb Movement Disorder and Patients with Obstructive Sleep Apnea Syndrome. Sleep Medicine, 13, 517-523. https://doi.org/10.1016/j.sleep.2011.11.018

[12] Rechtschaffen, A. and Kales, A. (1968) A Manual of Standardized Terminology, 
Techniques and Scoring System for Sleep Stage of Human Subjects. U.S. Government Printing Office, Washington, DC.

[13] The Report of an American Academy of Sleep Medicine Task Force (1999) Sleep-Related Breathing Disorders in Adults: Recommendations for Syndrome Definition and Measurement Techniques in Clinical Research. Sleep, 22, 667-689. https://doi.org/10.1093/sleep/22.5.667

[14] Sleep Disorders Atlas Task Force of the American Sleep Disorders Association (1992) EEG Arousals: Scoring Rules and Examples. Sleep, 15, 173-184. https://doi.org/10.1093/sleep/15.2.173

[15] Collard, P., Dury, M., Delguste, P., Aubert, G. and Rodenstein, D.O. (1996) Movement Arousals and Sleep-Related Disordered Breathing in Adults. American Journal of Respiratory and Critical Care Medicine, 154, 454-459. https://doi.org/10.1164/ajrccm.154.2.8756822

[16] Noda, A., Yasuma, F., Okada, T. and Yokota, M. (2000) Influence of Movement Arousal on Circadian Rhythm of Blood Pressure in Obstructive Sleep Apnea Syndrome. Journal of Hypertension, 18, 539-544. https://doi.org/10.1097/00004872-200018050-00005

[17] Kimoff, R.J., Cheong, T.H., Olha, A.E., Charbonneau, M., Levy, R.D., Cosio, M.G. and Gottfried, S.B. (1994) Mechanisms of Apnea Termination in Obstructive Sleep Apnea. Role of Chemoreceptor and Mechanoreceptor Stimuli. American Journal of Respiratory and Critical Care Medicine, 149, 707-714. https://doi.org/10.1164/ajrccm.149.3.8118640

[18] Johns, M.W. (1991) A New Method for Measuring Daytime Sleepiness: The Epworth Sleepiness Scale. Sleep, 14, 540-545. https://doi.org/10.1093/sleep/14.6.540

[19] Pietzsch, J.B., Garner, A., Cipriano, L.E. and Linehan, J.H. (2011) An Integrated Health-Economic Analysis of Diagnostic and Therapeutic Strategies in the Treatment of Moderate-to-Severe Obstructive Sleep Apnea. Sleep, 34, 695-709. https://doi.org/10.5665/SLEEP.1030

[20] Catcheside, P.G., Chiong, S.C., Mercer, J., Saunders, N.A. and McEvoy, R.D. (2002) Noninvasive Cardiovascular Markers of Acoustically Induced Arousal from Non-Rapid-Eye-Movement Sleep. Sleep, 25, 797-804. https://doi.org/10.1093/sleep/25.7.797

[21] Martin, S.E., Wraith, P.K., Deary, I.J. and Douglas, N.J. (1997) The Effect of Nonvisible Sleep Fragmentation on Daytime Function. American Journal of Respiratory and Critical Care Medicine, 155, 1596-1601. https://doi.org/10.1164/ajrccm.155.5.9154863

[22] Sforza, E. and Kriger, J. (1992) Daytime Sleepiness after Long-Term Continuous Positive Airway Pressure (CPAP) Treatment in Obstructive Sleep Apnea Syndrome. Journal of the Neurological Sciences, 110, 21-26. https://doi.org/10.1016/0022-510X(92)90004-5

[23] Seneviratne, U. and Puvanendran, K. (2004) Excessive Daytime Sleepiness in Obstructive Sleep Apnea: Prevalence, Severity, and Predictors. Sleep Medicine, 5, 339-343. https://doi.org/10.1016/j.sleep.2004.01.021

[24] Noda, A., Yasuma, F., Okada, T. and Yokota, M. (1998) Circadian Rhythm of Autonomic Activity in Patients with Obstructive Sleep Apnea Syndrome. Clinical Cardiology, 21, 271-276. https://doi.org/10.1002/clc.4960210408

[25] Punjabi, N.M., O’hearn, D.J., Neubauer, D.N., Nieto, F.J., Schwartz, A.R., Smith, P.L. and Bandeen-Roche, K. (1999) Modeling Hypersomnolence in Sleep-Disordered Breathing. American Journal of Respiratory and Critical Care Medicine, 159, 
1703-1709. https://doi.org/10.1164/ajrccm.159.6.9808095

[26] Yamamoto, H., Akashiba, T., Kosaka, N., Ito, D. and Horie, T. (2000) Long-Term Effects Nasal Continuous Positive Airway Pressure on Daytime Sleepiness, Mood and Traffic Accidents in Patients with Obstructive Sleep Apnoea. Respiratory Medicine, 94, 87-90. https://doi.org/10.1053/rmed.1999.0698 